\title{
Student Project: Instrumentation and Control of Solar-Powered Algae Biore- actor
}

\section{Dr. Richard Chiou, Drexel University (Eng. \& Eng. Tech.)}

Dr. Richard Chiou is Associate Professor within the Engineering Technology Department at Drexel University, Philadelphia, USA. He received his Ph.D. degree in the G.W. Woodruff School of Mechanical Engineering at Georgia Institute of Technology. His educational background is in manufacturing with an emphasis on mechatronics. In addition to his many years of industrial experience, he has taught many different engineering and technology courses at undergraduate and graduate levels. His tremendous research experience in manufacturing includes environmentally conscious manufacturing, Internet based robotics, and Web based quality. In the past years, he has been involved in sustainable manufacturing for maximizing energy and material recovery while minimizing environmental impact.

\section{Dr. Michael G Mauk P.E., Drexel University}

Michael Mauk is Assistant Professor in Drexel University’s Engineering Technology program.

\section{Prof. Tzu-Liang Bill Tseng, University of Texas, El Paso}

Dr. Tseng is a Professor and Chair of Industrial, Manufacturing and Systems Engineering at UTEP. His research focuses on the computational intelligence, data mining, bio- informatics and advanced manufacturing. Dr. Tseng published in many refereed journals such as IEEE Transactions, IIE Transaction, Journal of Manufacturing Systems and others. He has been serving as a principle investigator of many research projects, funded by NSF, NASA, DoEd, KSEF and LMC. He is currently serving as an editor of Journal of Computer Standards \& Interfaces.

Mr. carlos michael ruiz, Drexel University (Eng. \& Eng. Tech.)

Mr. Jean Carlo Espaillat,

Jean Carlo Espaillat Ureña graduated from Drexel University in Philadelphia, PA. He coursed engineering technology with a concentration in industrial engineering. During his time in Drexel University, Jean Carlo completed his thesis on how to accelerate algae growth in order to produce biofuels. His thesis was awarded first place in his school and was later on awarded second place in a university-wide competition. He now works in the Dominican Republic in Espalsa, SRL as the new projects manager.

\section{Mr. Senyu Wang}




\title{
Student Project: Instrumentation and Control of Solar-Powered Algae Bioreactor
}

\begin{abstract}
Energy harvesting biofuel systems use a constant amount of energy to monitor and control biofuel production. It is important to produce biofuels efficiently as these systems become much larger and sophisticated. Renewable energy resources improve environmental impact and sustainability. Improving solar cell efficiency through various measurement techniques expands the need for an independent energy harvesting system. Solar cells used to control microcontrollers and numerous system devices must be optimized to run an efficient system. The students developed a 3D printed circuit control board with a solar-powered algae bioreactor to monitor growth. The solar cells were common polycrystalline wafers that are available to consumers from online sources. The cells were then tested within an algal continuous flow system to determine effectiveness and efficiency as an energy resource. Examining such methods with an integrated solar bioreactor provides insight to students of practices towards improving solar cell efficiency through various fluid substances, transparent, and opaque material. In the process, students learn to use equipment for rapid prototyping. The project gives students knowledge and literacy in bio-fuel technology manufacturing as it has become an increasing area of interest.
\end{abstract}

\section{Introduction and Overview}

The student project was aimed to utilize solar energy through production of biomass and photovoltaics. Obtaining energy from biomass is through a system known as a photobioreactor (PBR). There has been considerable interest in PBRs. This is due to algae's high rate of growth with the production of lipids, which can be easily processed into bio-fuel [1]. The availability of sunlight limits productivity, so it is important to use it efficiently. During the summer season and in locations that gain more solar exposure, solar intensity is high and prepared for exploitation. Although solar intensity is high in specific locations, algae cannot absorb all of the solar spectrum, which is transferred into heat. Due to this inefficiency of solar energy usage, the algae culture overheats, and productivity becomes low [2]. For this reason, Wakayama et al. (2000) studied the effect of an oscillating light cycle from hours to seconds because several researchers have suggested the cycle arrangement to enhance the light conversion efficiency. They also proposed to combine the photobioreactor with solar cells that could utilize the light that was blocked for intermittent periods. The highest light conversion efficiency reported is $8 \%$, while the theoretical maximum is $10 \%$ [3]. Light intensity on the algae throughout the growing medium is a key parameter affecting algae growth. Algae generally need light intensities between $30 \mathrm{~W} / \mathrm{m}^{2}$ and 100 $\mathrm{W} / \mathrm{m}^{2}$ - which is around $1 / 10$ of the light intensity of direct sunlight. If light intensity levels are too high, there is poor additional growth and even a phenomenon known as photo inhibition. Photosynthesis is proportional to the number of suitable photons, not energy (as in e.g. silicon solar cells). Given this, for example, blue photons are no more "useful” in terms of photosynthetic output than red photons. Photosynthesis only uses a specific window of the solar spectrum photons between 400 and $700 \mathrm{~nm}$ (visible light) and this absorption spectrum is not uniform but has peaks at 450nm and 680nm [2]. The combination these two technologies improve algae growth 
and prevent photobleaching. The modulated light effect is meant to be achieved by placing black cardboards in a planar array onto a photobioreactor while moving the algae inside the photobioreactor in a linear flow. Thus, as the algae travel through the reactor, and they are exposed to light when they are in a region between the cardboards, then to dark when they are underneath them.

The project gives students an innovative technology that is produced on a large scale within industry. Using energy harvesting techniques and rapid prototyping devices, the students gain valuable experience in producing and enhancing the efficiency of a system with modern methods of manufacturing. The project is multidisciplinary and encompasses areas of bio, electrical, and mechanical engineering. It seeks to give students knowledge and improve literacy in bio-fuel manufacturing and production by investigating photosynthesis, respiration, and control board electronics for aquatic environment needs [5].

\section{Technical Description}

The project was a capstone project that extended for 3 consecutive terms. The tasks are shown in Figure 1's Gannt chart. Students worked with Chlorella due to its high oil retention, which is approximately $30 \%$ of its entire mass [4]. Algal cultures in photobioreactors have high

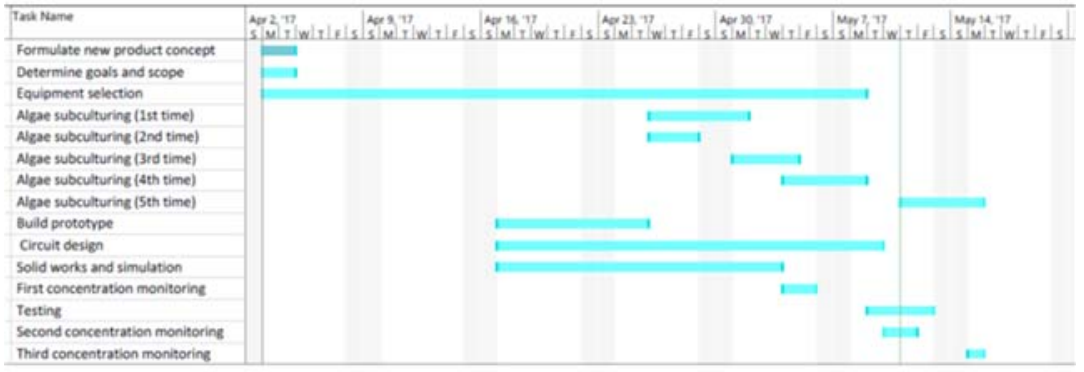

FIgURE 1 GANNT CHART

optical density, which results in the surface-cells absorbing most of the light, leaving only the residual part of the radiation for the cells on the bottom and limiting their growth. External layers are exposed to excess light and dissipate more than $50 \%$ of their photons to avoid radiation damage. Following this idea, alternation of light/dark cycle can be beneficial to the growth of the algae, as it will make the photosynthesis more efficient. The students sought to optimize algae output while effectively reducing the area of exposure Figure 2.
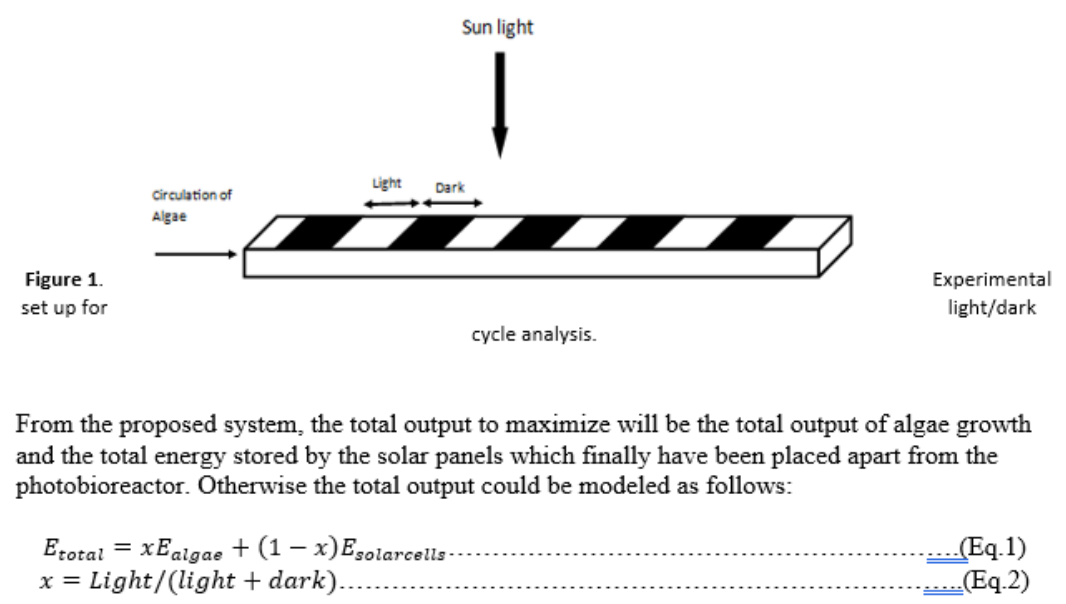

Figure 2 Light Cycle Exposure to Algae 
Different experiments were carried out to test how the adjusted light and dark cycles to optimize photosynthetic efficiency in algae growth in the photobioreactor. The different tests were completed by varying the spaces between the shadings and the flow rate to determine productivity in algae growth changes and compare it with a fully exposed system. With the use of CAD modeling, the students were able to perform fluid flow simulations with their designed bioreactors (Figure 3). Acrylic was chosen for the bioreactor because of its optical transparency. Sheets were ordered and cut using a CO2 laser cutter. The support frame was modeled then assembled with industrial polymer adhesives (Figure 4). Students became engaged as contact with mechanical, electrical, chemistry, and biology departments applied a diverse background of knowledge towards the project. An optical cell counter was used from the department of biology to determine concentration of algae for experimentation. The handheld device was used to correlate concentration with wavelength (Figure 5). Absorbance of wavelength was used with a miniaturized spectrophotometer (Figure 6). The data collected from the cell counter and the spectrophotometer was used to calibrate solar intensity and algal density with an Arduino control board. The information was used to determine the overall exposure through the acrylic material and the algae to the photovoltaics. The exposure determined the efficiency and required power to run the control board to operate the system. Students investigated various available photovoltaics available to the market to integrate into the system. After cost and power requirements were analyzed, they then continued to pursue 3D printing a control board circuit.

The 3D-PCB printer is called Squink. A manual for using the device was created for rapid prototyping. The $3 \mathrm{D}$ printing device prints conductive ink onto a substrate from a GRBL file. DipTrace was used to create the circuit board and its layers. The circuit was then converted to a PCB file using auto-router. The file was then $3 \mathrm{D}$ modeled to determine its size with the given components. DipTrace has a high-quality shape-based autorouter and the Grid Router suitable for simple PCBs and

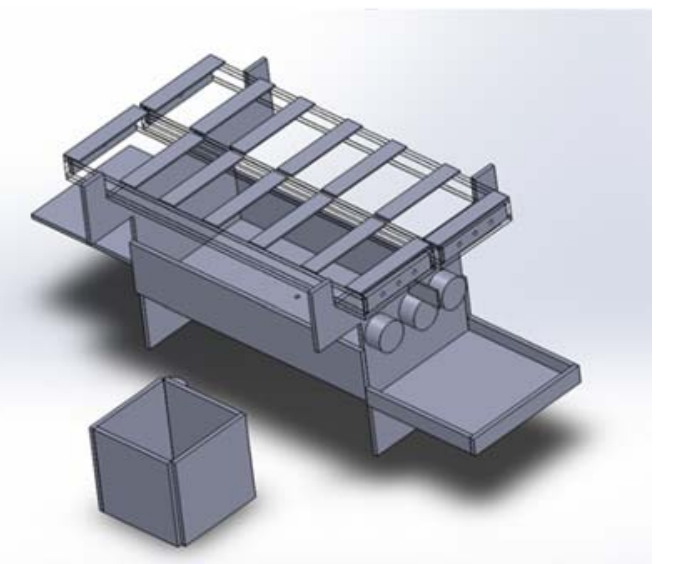

Figure 3 CAD design (USED for FlUid SimULATION)

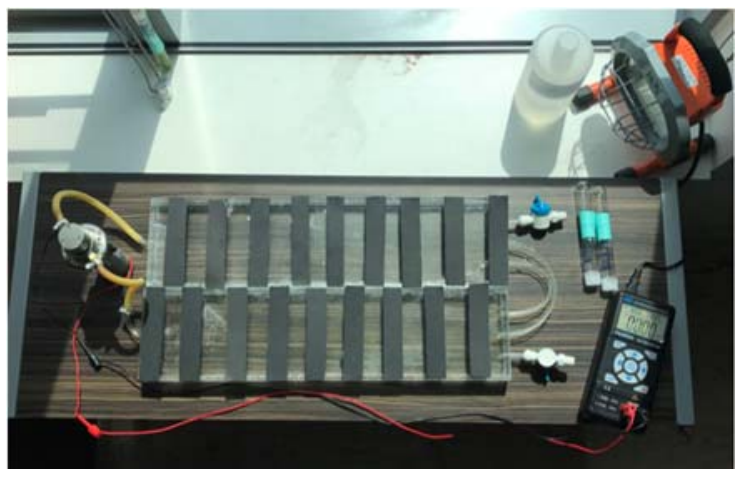

FIGURE 4 ASSEMBLED BIO-REACTOR WITH PREPLACEMENT OF PVS

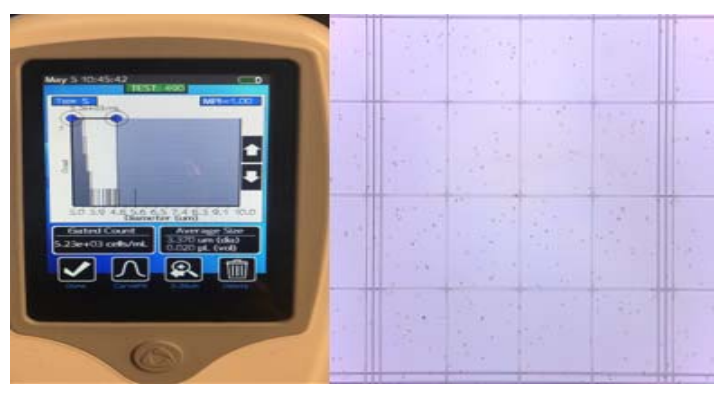

FIGURE 5 HANDHELD CELL COUNTER DEVICE
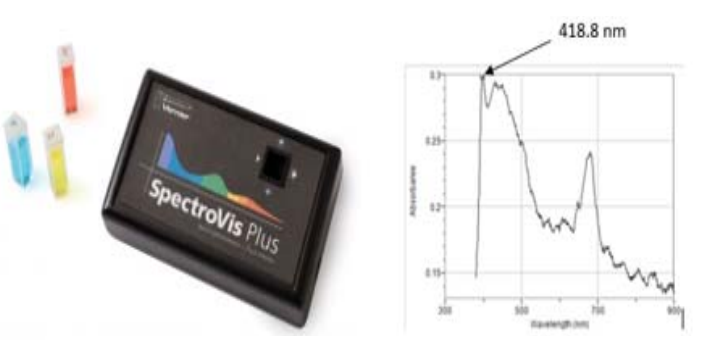

FIGURE 6 SPECTROPHOTOMETER AND WAVELENGTH ABSORBANCE 
single-layer boards with jumper Designing a PCB 39 . Single-layer boards usually have longer traces but give many other benefits for prototyping. DipTrace has several verification options on different levels of PCB design (Figure 7). For example, Design Rule Check (DRC). It verifies object sizes, length/phase parameters of high-speed nets, and clearances between different objects according to user-defined rules. The DRC results in the error-report list. Violations are marked with

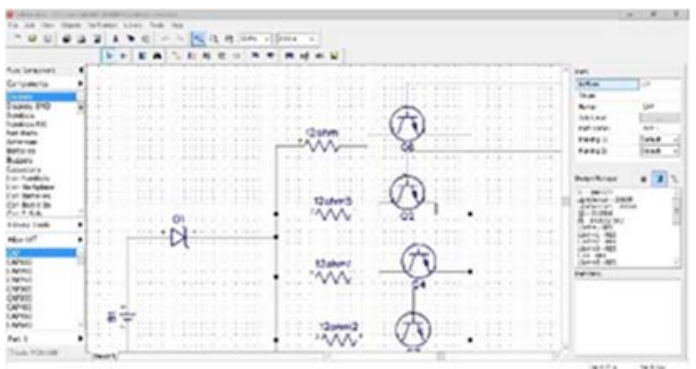

Figure 7 Designed PCB Circuit

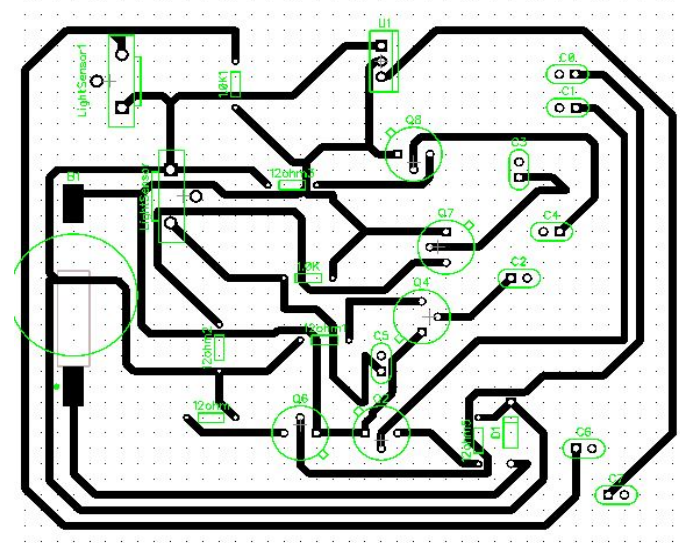

Figure 8 ROUTING TRACE

(CONTROL BOARD) in-depth (Figure 9). Design Rule Check (DRC) with comparing to source schematic ensure maximum quality of the final design. DipTrace automatically places a 3D model to fit the pattern's drawing. Students entered appropriate values into the corresponding fields on the 3D Model Properties section (shift, angle, and scale for each axis). In this case, the resistor needed to rotate 90 degrees and shift it up a bit. Specify 90-degree $\mathrm{Z}$ Angle and 0.03 inch Z Shift to complete this circuit.

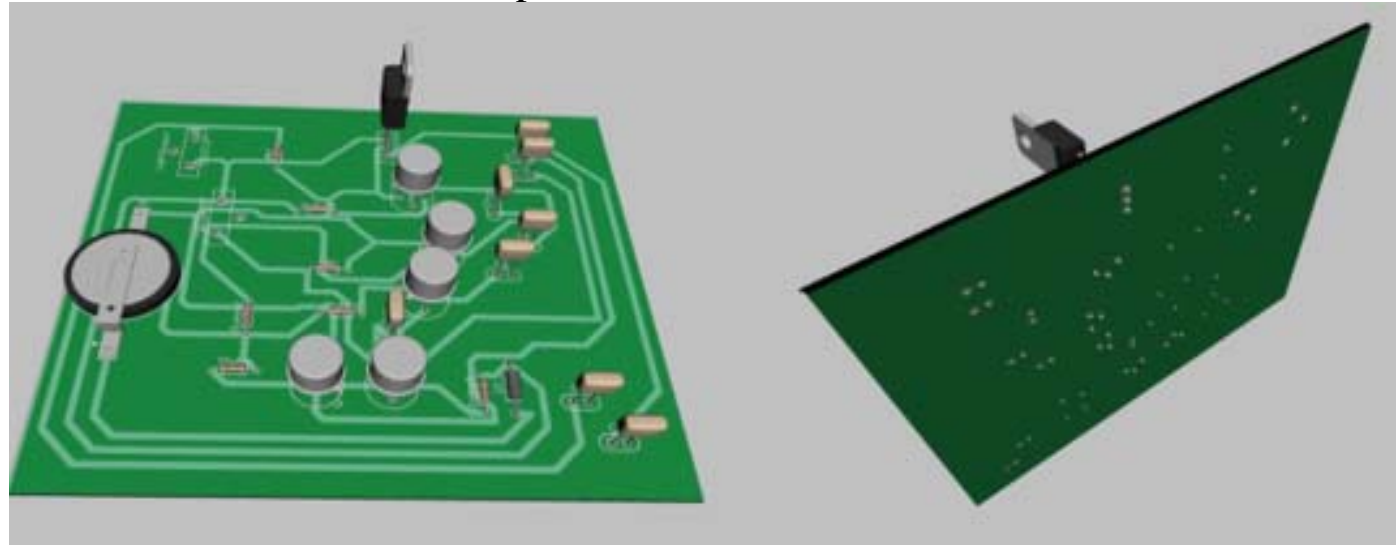

FiguRE 9 3D MODEL OF CONTROL BOARD

Modeled PCB layering was self-learned as students became familiar with the intricate process of component layout and layered printing. The program gave them optimization of board layout to fit the parameters of their reactor without sacrificing quality. An instructional table was created by 
student of the project to help others seeking to 3D print a PCB (Table 10). The table is useful to future 3D printing circuit projects.

\begin{tabular}{|c|c|}
\hline Layer: & Description: \\
\hline Top Assy & $\begin{array}{l}\text { This is assembly layer, it includes all shapes/texts placed on the Top } \\
\text { Assy as well as objects defined in the "View } \backslash \text { Assembly Layers" } \\
\text { main menu item. Assembly layer in this project includes the board } \\
\text { outline because it is selected in the "View } \backslash \text { Assembly Layers" main } \\
\text { menu item, but you can select another object or hide the board } \\
\text { outline on this layer. }\end{array}$ \\
\hline Top Silk & $\begin{array}{l}\text { Includes pattern shapes, texts and all other shapes and texts placed } \\
\text { in the Top Silk layer. Do not change these settings, and press } \\
\text { Preview. Notice that if you use the TrueType fonts, some parts of } \\
\text { the text can be invisible (depends on the font and size), you should } \\
\text { make Recognize Accuracy value a bit smaller, but do not apply } \\
\text { minimums. }\end{array}$ \\
\hline Top Mask & $\begin{array}{l}\text { This is a solder mask layer. It is generated automatically, based on } \\
\text { pads, custom pad settings, and common Solder Mask Swell } \\
\text { parameter, defined in the Export Gerber dialog box. This layer also } \\
\text { includes shapes placed in the solder mask layer. We should uncheck } \\
\text { the Vias box (exclude vias from the export) because vias are usually } \\
\text { covered with the solder mask. }\end{array}$ \\
\hline Top Paste & $\begin{array}{l}\text { This layer is used for SMD pads only, so we can check Paste Mask for } \\
\text { SMT Pads only. }\end{array}$ \\
\hline Signal layers (Top, Bottom, etc.) & $\begin{array}{l}\text { These are copper layers. Notice that Pad/Via Holes item in the } \\
\text { Objects section should be checked only if you plan to drill holes } \\
\text { manually (not using a PCB house). If Pad/Via Holes check box is } \\
\text { checked, two Gerber layers will be created inside one Gerber file: } \\
\text { Positive Drawing and Hole Clearing. The second layer is used to } \\
\text { remove artifacts over the drill holes. Manufacturers prefer Gerber } \\
\text { files without pad/via holes }\end{array}$ \\
\hline Additional Info & $\begin{array}{l}\text { Bottom Paste, Mask, Silk and Assy layers are just like their analogs } \\
\text { from the top side. By default all text objects in Bottom layers are } \\
\text { flipped Board Outline layer includes the board outline with defined } \\
\text { width. Board layer includes the board as a filled polygon. }\end{array}$ \\
\hline Top/Bottom Dimensions & $\begin{array}{l}\text { layers created especially for dimensions. These layers are blank in } \\
\text { our case because the current project does not have any dimensions } \\
\text { on the design area. Top / Bottom Dimensions can help some } \\
\text { manufacturers to avoid mistakes in sizes. }\end{array}$ \\
\hline
\end{tabular}

TABLE 1: InstructionAl LAYER GUIDELINE FOR 3D PRINTING PCB

The board was then 3D printed using the device with a network IP interface. The processes included initial design parameters for the substrate, pre-heating, device calibration, determining conductivity of line width, printing, and curing. The student also developed a detail manual for 
this device to assist others. The circuit board was then printed. After the printing was completed, the components were added using a conductive thermal active paste (Figure 10-A). The process is quick to complete as it takes nearly an identical amount of time to print a PCB as it does a small model from an FDM printer (40 -60 minutes).

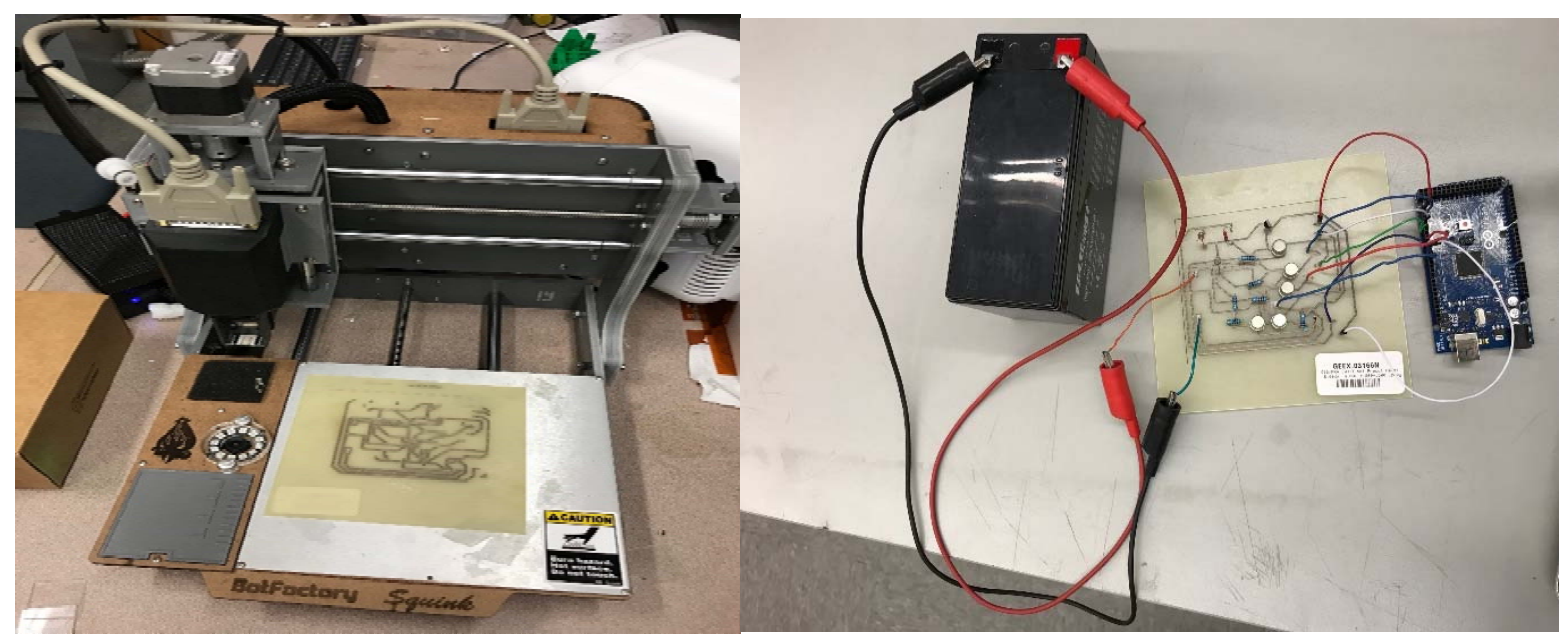

Figure 10 A.) 3D Circuit BoArd Printer (Left), B.) PRINTED BoARd With COMPONENTS (RIGHT)

To protect the device the group used a laminate film to bond to the surface of the substrate. It was bonded using a heat gun to 120 degree-C. The circuit was first tested with a Power supply (Battery) before mounting onto the setup and connecting the solar panels to it (Figure 10-B). The 3D printed control board was then ready for integration into the bioreactor control unit.

The solar cells were selected using the following standards:

- High conversion efficiency

- Excellent spectral response in all wavelengths

- Low reverse current to avoid hot spot

- Precise printing and superior silver contact to assure ease of soldering and high adhesion

- All products pass visual inspection

- $100 \%$ inspected for shunt resistance and reverse current

- PID-free products which pass PID test up to 1,000hrs. (Test conditions: $-1000 \mathrm{~V}$, Temperature: 85C, Moisture: 85\%)

- Proven track-record of high quality, performance and reliability

- High parallel resistance selection: ensures cells with high output performance under low illuminance conditions

- Stable performance in extreme environmental conditions (high temperature, high moisture, extreme cold)

- Conform to RoHS/SVHC standards 
Students sought assistance from a laboratory RA for safety inspection and suggestions of the components prior to testing. The device was encased for safety and tested prior to testing (Figure11).

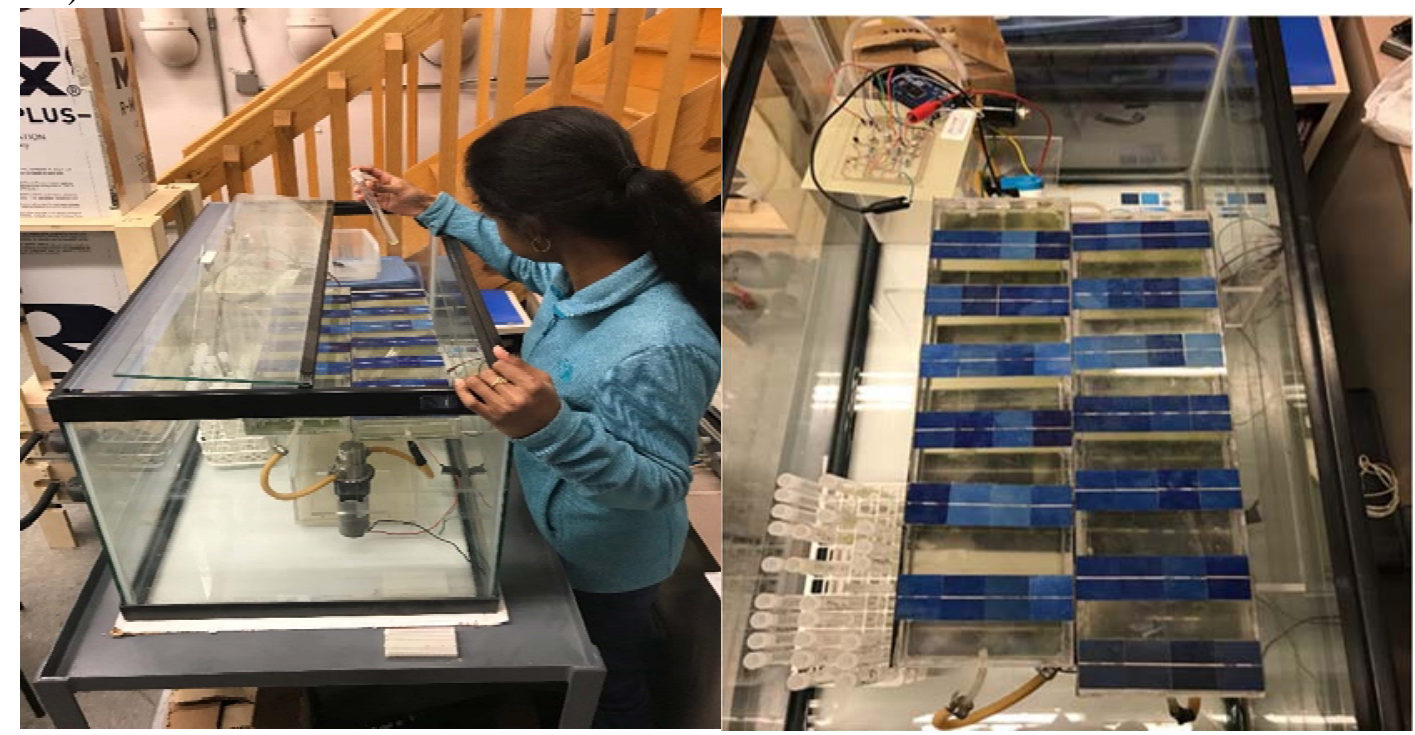

Figure 11 SAfety Inspection Prior to Testing

A market analysis was completed to determine manufacturing costs of the device with a specified number of units to produce (Table 2). The costs are much more affordable than current marketed bioreactors.

\begin{tabular}{|c|c|c|c|c|}
\hline \multicolumn{5}{|c|}{ Initial Capital Investment: } \\
\hline \multirow{2}{*}{ Small batch production } & \multicolumn{4}{|c|}{ Units produced: } \\
\hline & per unit costs & 25 units produced: & 50 units produced: & 100 units produced: \\
\hline raw materials & $\$ 573.79$ & $\$ 14,344.75$ & $\$ 28,689.50$ & $\$ 57,379.00$ \\
\hline Labor & $\$ 75$ & $\$ 1,875.00$ & $\$ 3,750.00$ & $\$ 7,500.00$ \\
\hline Packaging: & & & $\$ 0.00$ & $\$ 0.00$ \\
\hline Box & $\$ 0.90$ & $\$ 22.50$ & $\$ 45.00$ & $\$ 90.00$ \\
\hline $\begin{array}{l}\text { Peanut package } \\
\text { (biodegradable) }\end{array}$ & $\$ 2.98$ & $\$ 74.50$ & $\$ 149.00$ & $\$ 298.00$ \\
\hline $\begin{array}{l}\text { Laser Cut Service ( } \$ 1 \text { per } \\
\text { minute; } 30 \text { minutes for all } \\
\text { parts) }\end{array}$ & $\$ 30$ & $\$ 750.00$ & $\$ 1,500.00$ & $\$ 3,000.00$ \\
\hline Total cost & $\$ 682.67$ & $\$ 17,066.75$ & $\$ 34,133.50$ & $\$ 68,267.00$ \\
\hline
\end{tabular}

\section{Summary}

The Instrumentation and Control of Solar-Powered Algae Bioreactor project presented a group of multidisciplinary students with an unfamiliar territory of knowledge. Bio-fuel is often neglected in curriculums due to the misconception of required bio-related knowledge and instrumentation to support such a device. It is often seen as time consuming as results are dependent on time due to 
growth of cells. The students applied electrical and mechanical knowledge to enhance a system to provide better results than current marketed methods. They were able to establish a communicative relationship with other departments to learn how to use various devices and quantify algae cells into an easy to read system for their control board. Biofuel is an important topic of discussion as alternatives fuels are consistently investigated to reduce pollution. The students were able to implement a solar powered control board using advanced 3D circuit printing and CO2 laser cut materials to improve the rate of algae production within a scaled system that is considered desktop and portable. The project was ranked first in the department and came in second place within the school's engineering competition. The students did well to establish a foundation of supportive experts to become comfortable within unfamiliar material. The project was an enjoyment for students as they continuously engaged in literature reviews and remained in routine contact with bio experts for feedback. They were initially unware of the amount of funding invested into biofuels and the gaining popular interest from industry. One of the students was surprised by the amount of money invested in bio-fuel $R \& D$ from a company, in which he was seeking employment. In closing, given the costs of materials and time for experimentation, schools should not be apprehensive towards implementing biofuel projects. Bio-fuels have become a large area of interest for development. Thus, students should be become familiarized with such innovative modern technology. 


\section{References}

[1] Lee, C.G: and B.Palsson, "High-density algal photobioreactors using light-emitting Diodes”. Biotechnology and Bioengineering; 44, p1161-1167, John Wiley \& Sons, Inc, 1994.

[2] Carels, N. (2011, August 1). The Challenge of Bioenergies. Retrieved from:

http://www.intechopen.com/books/biofuel-s-engineering-process-technology/the-challenge-of-bioenergies-anoverview

[3] Debabrata, D. \&Namita, K. \&Chitralekh. 2014. Biohydrogen Production: Fundamentals and Technology Advances.Pg 249

[4] Malcata FX. Microalgae and biofuels: a promising partnership? Trends Biotechnol 29: 542-549.

\{5\} P. W. Sean Chamberlin, "The Algae-in-a-Bottle Experiment: A High-Impact Learning Acitiviy," 22 December 2016. [Online]. Available: https://d32ogoqmya1dw8.cloudfront.net/files/sp/pkal/pogil/examples/algae-inbottle_experiment_descript.pdf. [Accessed 15 January 2017]. 


\section{Appendix A:}

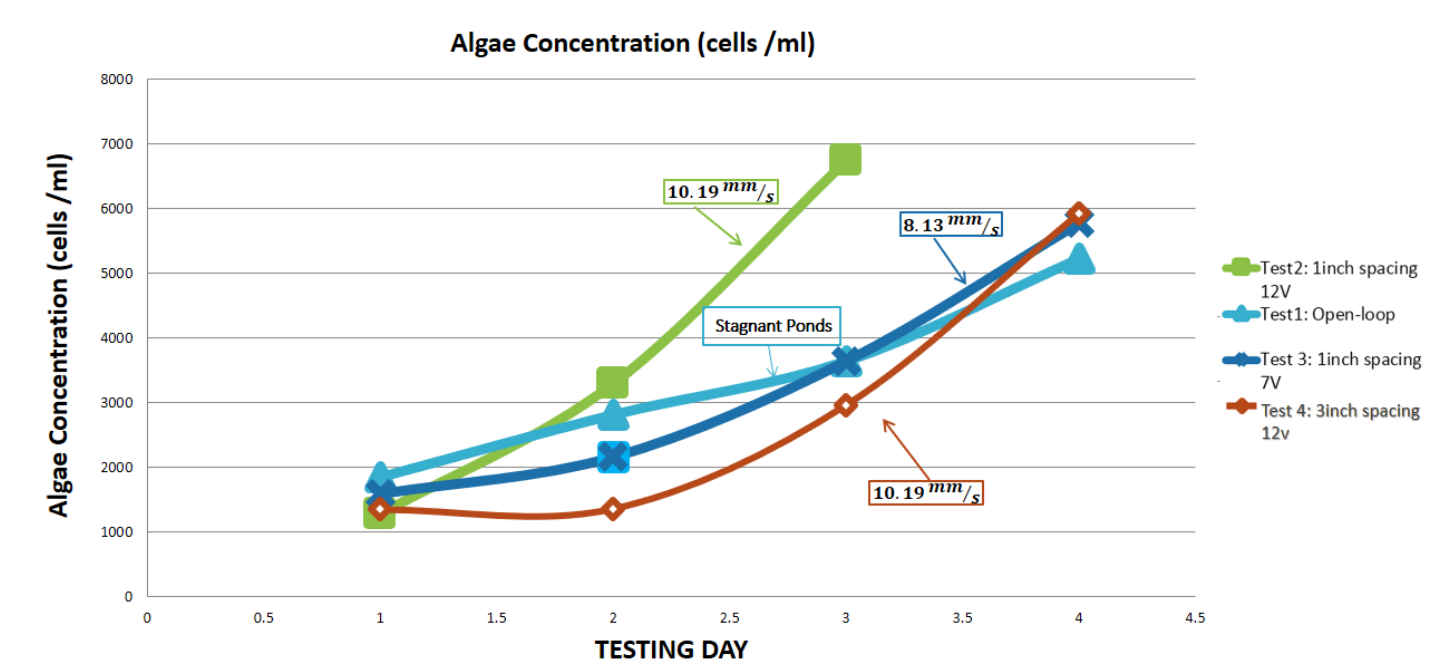

Figure 12 Algae Concentration With VARied Oscillating Light

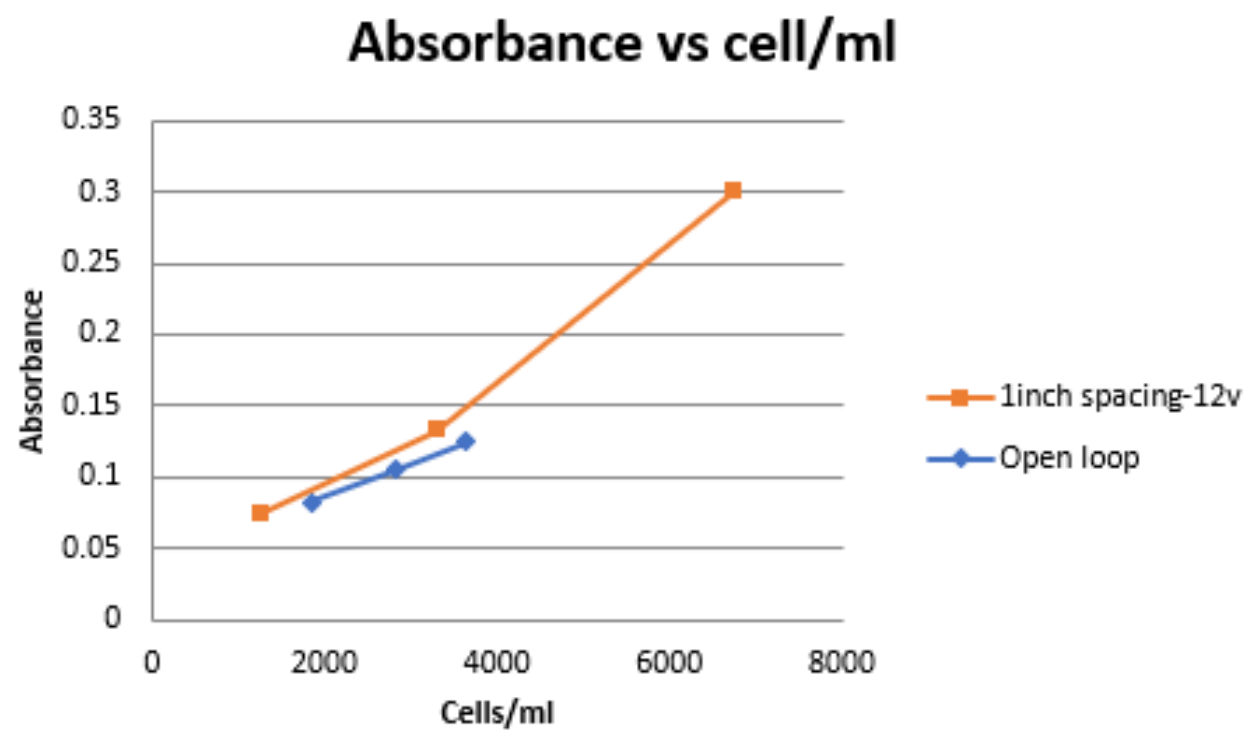

Figure 13 Algae Absorbance With Varied Oscillating light 


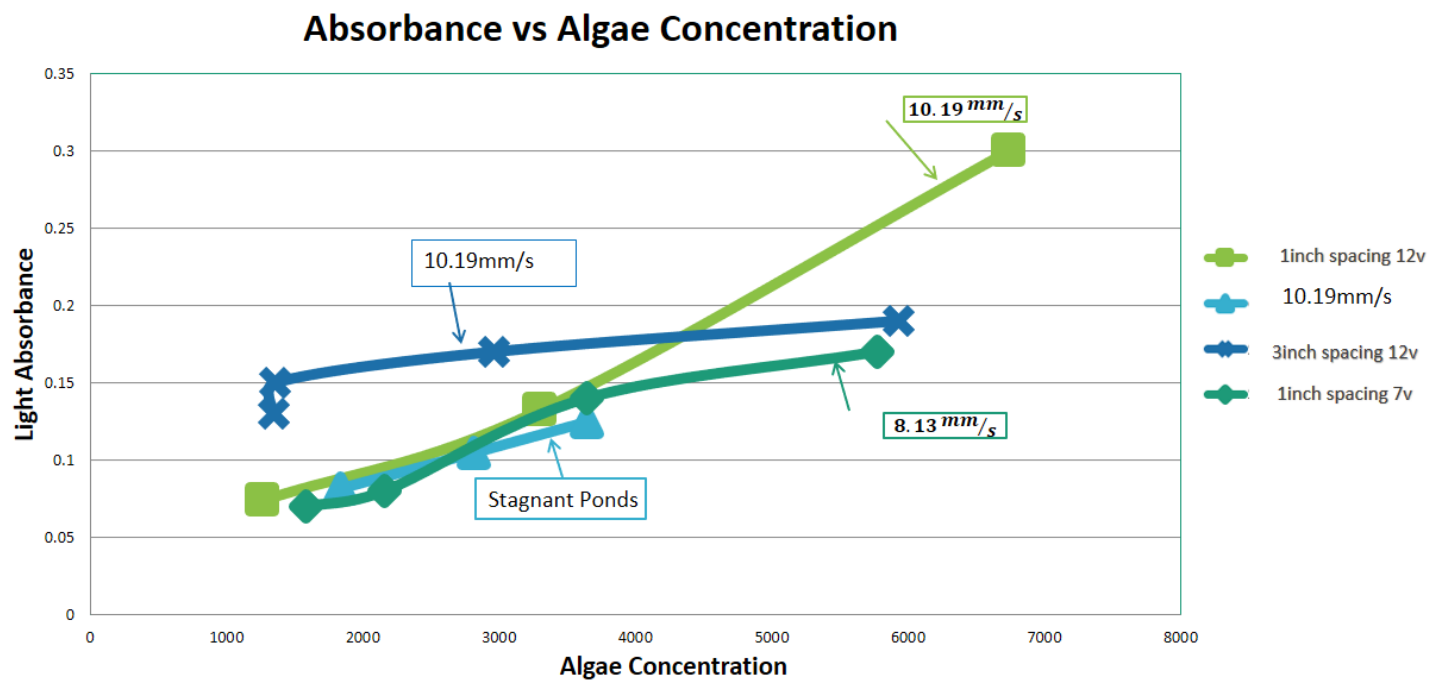

Figure 14 Absorbance ANd ConCEntration for CALIbration 